\title{
BMJ Open Does tonsillectomy reduce medical care visits for pharyngitis/tonsillitis in children and adults? Retrospective cohort study from Sweden
}

\author{
Eirik Østvoll (D) ,,2 Ola Sunnergren,, Joacim Stalfors ${ }^{2,5}$
}

To cite: Østvoll E, Sunnergren 0 , Stalfors J. Does tonsillectomy reduce medical care visits for pharyngitis/tonsillitis in children and adults? Retrospective cohort study from Sweden. BMJ Open 2019:9:e033817. doi:10.1136/ bmjopen-2019-033817

- Prepublication history for this paper is available online. To view these files, please visit the journal online (http://dx.doi org/10.1136/bmjopen-2019033817).

Received 26 August 2019 Revised 01 October 2019 Accepted 18 0ctober 2019

Check for updates

(C) Author(s) (or their employer(s)) 2019. Re-use permitted under CC BY-NC. No commercial re-use. See rights and permissions. Published by BMJ.

\section{Department of}

Otorhinolaryngology - Head and Neck Surgery, Sahlgrenska University Hospital, Göteborg, Sweden

${ }^{2}$ Institute of Clinical Sciences, Sahlgrenska Academy at the University of Gothenburg, Göteborg, Sweden

${ }^{3}$ Department of

Otorhinolaryngology, Ryhov

County Hospital, Jönköping,

Sweden

${ }^{4}$ Department of Clinical and

Experimental Medicine,

Linköping University, Linköping,

Sweden

${ }^{5}$ Sheikh Khalifa Medical City, Ajman, United Arab Emirates

Correspondence to

Dr Eirik Østvoll;

eirik_ostvoll@hotmail.com

\section{ABSTRACT}

Objective To assess the effectiveness of tonsillectomy/ adenotonsillectomy in reducing medical care visits for pharyngitis or tonsillitis in children and adults with chronic/ recurrent tonsillitis.

Design Retrospective cohort study.

Setting Data were retrieved from the VEGA register, a comprehensive regional cohort in Sweden.

Participants 1044 children ( $<15$ years) and 2244 adults. Intervention Tonsillectomy/adenotonsillectomy compared with no surgical treatment.

Main outcome measures Changes in yearly mean rates of medical care visits due to pharyngitis/tonsillitis.

Results In children, there was a significant decrease in the yearly mean medical care visits rate from 1.93 (1.82 to 2.04 ) before surgery to 0.129 (0.099 to 0.165$)$ after surgery, with a mean change of $-1.80(-1.90$ to -1.69$)$, $\mathrm{p}<0.0001$. In patients who did not undergo surgery, the corresponding mean change was $-1.51(-1.61$ to -1.41$)$, resulting in a mean difference in the change in visit rates between the intervention and control groups of -0.283 $(-0.436$ to -0.135$), p=0.0002$. In adults, a significant decrease in the yearly mean medical care visit rate was observed from 1.45 (1.39 to 1.51) before surgery to 0.152 ( 0.132 to 0.173 ) after surgery, with a mean change of -1.30 ( -1.36 to -1.24$), p<0.0001$, compared with -1.18 $(-1.24$ to -1.13$)$ in the control group. The difference in the change in yearly mean visit rate between the surgical and non-surgical groups was $-0.111(-0.195$ to -0.028$)$, $p=0.0097$. The subgroup analysis showed a greater effect of surgery in children, in patients with a higher number of medical care visits before surgery and in the first year of follow-up.

Conclusion In this cohort of patients moderately or less affected with chronic/recurrent tonsillitis, the effectiveness of tonsillectomy/adenotonsillectomy in reducing medical care visits for pharyngitis and tonsillitis compared with no surgical treatment was low and of questionable clinical value.

\section{INTRODUCTION}

Recurrent and chronic tonsillitis are treated with either expectancy, antibiotics or tonsillectomy. The strength of evidence behind performing tonsillectomy for these indications is moderate. ${ }^{1-6}$ In the updated Cochrane

\section{Strengths and limitations of this study}

- This is the first population-based cohort study comparing medical care visits for throat infections after tonsillectomy with medical care visits in a matched cohort of nonsurgically treated patients.

- This study supports the previous findings that (adeno)tonsillectomy has no major clinical benefit in reducing medical care visits over watchful waiting in children with fewer episodes of pharyngitis/ tonsillitis.

- This is the first study of the long-term effect of tonsillectomy for chronic/recurrent throat infections in adults.

- The study design, a retrospective cohort study, does not allow control of the circumstances leading to a tonsillectomy decision, and it is possible that patients who underwent surgery had 'more severe' disease compared to patients that did not undergo surgery.

- No specific code for recurrent tonsillitis exists in the International Classification of Diseases 10th Revision coding system (ICD-10); hence, differentiation between chronic and recurrent tonsillitis as indication for surgery was not possible.

review (2014), Burton et al conclude that the number of sore throat episodes is reduced the first year after surgery in children, while there is insufficient information to draw firm conclusions about the effectiveness of the procedure in adults. ${ }^{1}$ Spontaneous resolution of symptoms has been noted as one reason for the moderate effect of surgery, and the updated guidelines from the American Academy of Otolaryngology-Head and Neck Surgery make strong recommendations towards watchful waiting in less severely affected children. ${ }^{6} \mathrm{~A}$ few randomised controlled trials have investigated the effect of tonsillectomy on recurrent or chronic tonsillitis, but these are limited by divergent designs, a high level of cross over between groups or short follow-up. ${ }^{3}$ 7-10 However, 
tonsillectomy for tonsillitis is a common procedure with great variation in incidence. ${ }^{11}{ }^{12}$ Most clinical guidelines advocate using the number of infections per year to predicate if tonsillectomy is indicated, often with reference to the studies of Paradise et $a l^{578}$ Variations exist, however, between countries in the number of infections needed to qualify for surgery and the recommended duration of watchful waiting. ${ }^{5}$ Furthermore, evidence derived from studies performed on children is extrapolated to adults since the evidence for adults is insufficient. ${ }^{13}$ Thus, there is a need for studies on the efficacy of tonsillectomy on the indication tonsillitis in both children and adults, especially considering the high number of surgeries performed based on this indication worldwide each year.

The aim of this study was to compare the number of medical care visits for pharyngitis and tonsillitis before and after tonsillectomy, and to compare the number of postoperative medical care visits in surgically treated patients with visits in patients with the same history of throat infections that did not undergo tonsillectomy. The hypothesis was that tonsillectomy reduces the number of medical care visits for pharyngitis and tonsillitis.

\section{METHODS}

\section{Study design}

This is a retrospective cohort study based on a comprehensive regional cohort in Sweden. Data were retrieved from the regional medical database VEGA covering 1.6 million inhabitants in Västra Götaland. The database is managed by the regional public healthcare authority and contains diagnostic ICD codes for all visits and NOMESCO codes ${ }^{14}$ for all surgical procedures performed in primary care and specialised inpatient and outpatient care in the region, including that provided by private caregivers. Reporting to VEGA is a prerequisite for reimbursement for any medical care provided, and the coverage is considered equal to the validated National Patient Register in Sweden, with $80 \%$ coverage of specialised outpatient care and nearly complete coverage of inpatient and primary care. $^{15}$

\section{Intervention and control groups}

Data for all patients with a medical care visit due to pharyngitis or tonsillitis between 1 January 2011 and 31 December 2017 were retrieved from the VEGA register (flow chart in figure 1).

From this population, two groups were formed. All patients who underwent tonsillectomy or adenotonsillectomy (only children) based on the indication of chronic tonsillitis were classified as the intervention group, while the patients without a registered tonsil surgery constituted the patient-pool available for creating a control group. For all patients in the control group, one of the visits was randomly classified as a fictitious tonsillectomy to enable comparison with the intervention group. To assure a minimum of 2 years of preintervention observation and 1 year of postintervention observation, only patients with an actual or fictional tonsillectomy between 1 January 2013 and 31 December 2016 were further included in the analysis.

A caliper matching procedure based on the characteristics of the patients in the intervention group (age, gender, number of medical care visits) was performed on the patients in the control group. The matching of gender and number of medical care visits were prioritised and strictly enforced (1:1). All patients with previously registered tonsil surgery between 1 January 2000 and 31 December 2012 were excluded from the study, as were adults who underwent adenotonsillectomy and patients of all ages who underwent tonsillotomy with or without adenoidectomy.

In the intervention group, one visit was subtracted to adjust for the visit related to the scheduling of surgery (a visit not related to an acute episode of infection). In the control group, the medical visit randomised as a fictitious surgical event was still counted as a visit due to pharyngitis or tonsillitis. Only one visit was allowed for each date and if more than one diagnostic code for pharyngitis/tonsillitis was found, codes from specialised care were given priority over primary care. If conflict in primary care, ICD codes for acute tonsillitis (J03X) was prioritised over acute pharyngitis (J02X) and chronic tonsillitis (J350) were given the lowest priority.

Both the intervention and control groups were divided into three different categories based on the number of medical care visits for pharyngitis/tonsillitis in the 2-year run-in period before surgery/fictitious surgery. Category A included patients with 1-3 visits, category B included patients with 4-6 visits and category $\mathrm{C}$ included patients with 7 or more visits before surgery/fictitious surgery.

\section{Statistical analysis}

The primary analyses were the change in yearly mean medical care visit rates after surgery and comparison of the change in visit rates between the surgical and nonsurgical groups. These calculations were based on up to 3 years of follow-up after surgery/fictitious surgery, and patients contributed with their maximum duration of follow-up years. Subgroup analyses were performed separately for children and adults based on the number of preoperative medical care visits (category) and the year of follow-up. For categorical variables, n (\%) is presented, and for continuous variables, the mean with $95 \% \mathrm{CI}, \mathrm{SD}$, median, minimum and maximum are presented. Mean differences between groups are given with 95\% CI. For comparison between two groups, the Mantel-Haenszel $\chi^{2}$ test was used for ordered categorical variables, Fischer's non-parametric permutation test was used for continuous variables, Fisher's exact test was used for dichotomous variables and the $\chi^{2}$ test was used for non-ordered categorical variables. For comparison of changes in both the surgical and control groups, Fisher's non-parametric permutation test for paired observations was used. All significance tests were two sided and conducted at the 


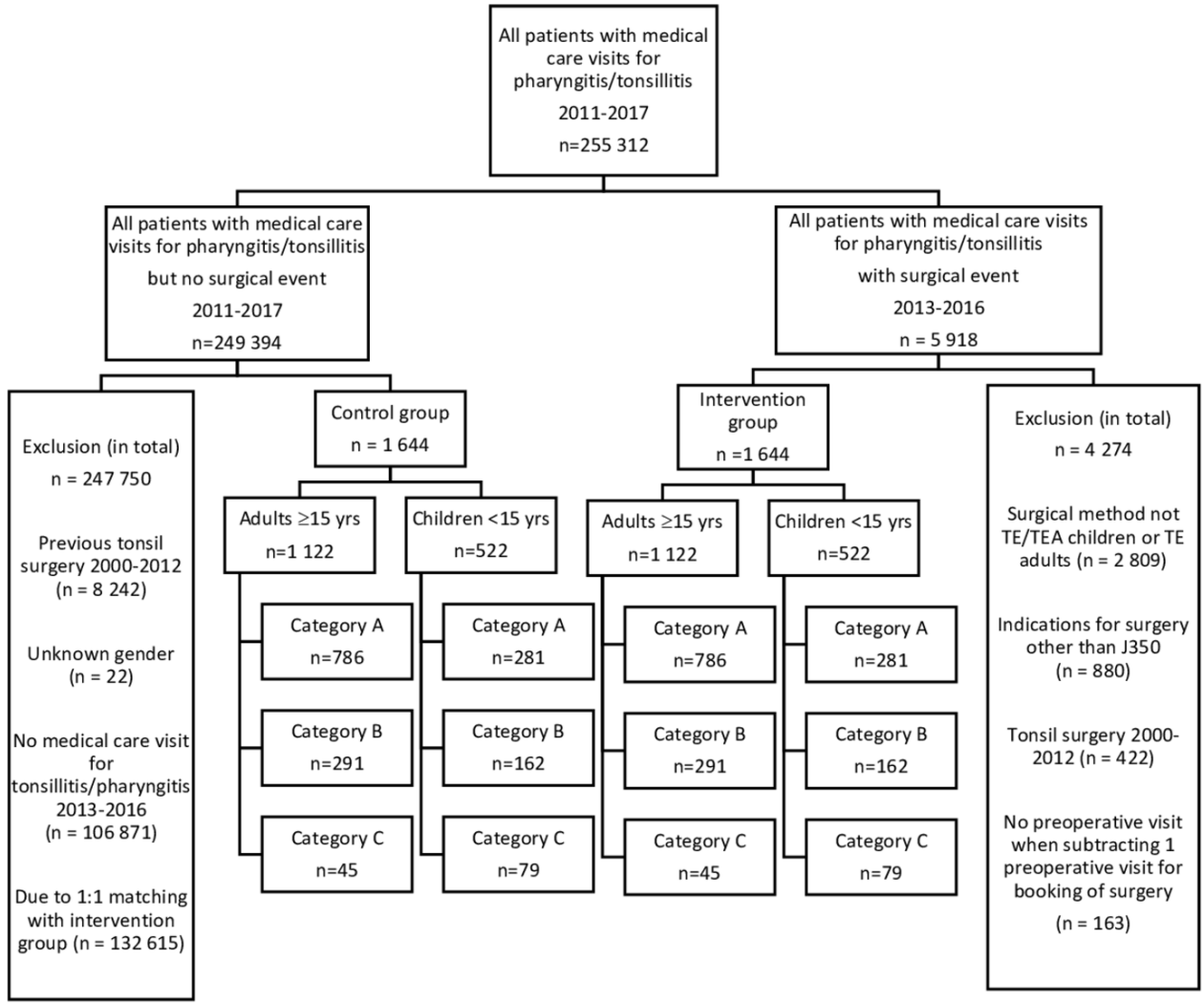

Qualifying ICD codes for medical care visit for pharyngitis or tonsillitis

J02 Acute pharyngitis

J020 Streptococcal pharyngitis

J028 Acute pharyngitis, other microorganisms

J029 Acute pharyngitis unspecified
J03 Acute tonsillitis

J030 Streptococcal tonsillitis

J038 Acute tonsillitis, other microorganisms

J039 Acute tonsillitis unspecified

Figure 1 Flow chart of the study design. All patients with medical care visits for pharyngitis or tonsillitis with the given qualifying ICD10 codes were included and divided into groups of children and adults, and further into intervention and controls groups. Category A are patients with 1-3 medical care visits before surgery or fictive operation date. Category B had 4-6 medical care visits and category $C$ had $7+$ medical care visits. Numbers $(n)$ are presented for follow-up year 1 for each category. $\mathrm{TE}$, tonsillectomy; TEA, adenotonsillectomy.

5\% significance level. Calculation of CIs for continuous variables was based on bootstrapping of 10000 replicates picking the $2.5 \%$ and $97.5 \%$ percentiles of the 10000 mean differences. A forest plot was used to demonstrate incidence rates per 100 person years, rate ratio, relative rate reduction $(R R R=1 R R)$ and number needed to treat (NNT=1/absolute rate reduction), defined in this study as the number of patients needed to undergo tonsillectomy to save one medical care visit for pharyngitis/tonsillitis. Histograms were chosen to present the distribution of the number of postoperative medical care visits and registered ICD10 codes. Data were sorted, grouped and analysed with the statistical software SAS V.9.4.

Sensitivity analyses were performed in children to determine whether adenoid surgery affected the outcome. No statistically significant differences in the number of postoperative medical care visits between tonsillectomy with or without adenoidectomy were found; therefore, subsequent analyses were performed on the pooled group of children (tonsillectomy and adenotonsillectomy).
To determine if the loss of patients with shorter follow-up affected the study population and the results for follow-up years 2 and 3, a drop-out analysis was performed. Statistical analyses showed a significant higher number of dropouts in category A (1-3 visits) years 2 and 3 compared with category $\mathrm{B}$ (3-6 visits) and $\mathrm{C}(7+$ +visits $)(\mathrm{p}<0.0016)$. A higher number of dropouts were also seen in the intervention group compared with the control group year 2 (4.8\% (0.3 to 9.2 ) and year 3 (5.8\% (2.3 to 9.4)). For the variable gender, significantly higher proportion of females dropped out year 2 of follow-up (5.1\% (0.9 to 9.3)), but not year 3 . When comparing the remaining patients in the intervention and control groups years 2 and 3, no statistically significant differences were seen for any of the baseline variables, and the groups were deemed comparable years 2 and 3 , even though no longer matched 1:1.

\section{Patient and public involvement}

It was not appropriate or possible to involve patients or public in designing or executing this study. 
Table 1 The general characteristics of the study population

\begin{tabular}{|c|c|c|c|c|c|c|}
\hline \multirow{2}{*}{$\begin{array}{l}\text { General characteristics } \\
\text { Of the study population }\end{array}$} & \multicolumn{3}{|c|}{ Children (tonsillectomy/adenotonsillectomy) } & \multicolumn{3}{|c|}{ Adults (tonsillectomy) } \\
\hline & Intervention group & Control group & $P$ value & Intervention group & Control group & $P$ value \\
\hline & $\mathrm{n}=522$ & $\mathrm{n}=522$ & & $n=1122$ & $\mathrm{n}=1122$ & \\
\hline $0-4$ & $137(26.2 \%)$ & $137(26.2 \%)$ & & & & \\
\hline $5-6$ & $126(24.1 \%)$ & $126(24.1 \%)$ & & & & \\
\hline $40-$ & & & & $76(6.8 \%)$ & $76(6.8 \%)$ & \\
\hline Age at surgery & $\begin{array}{l}7.75(3.49) \\
6.98(1.70 \text { to } 14.99) \\
(7.45 \text { to } 8.05)\end{array}$ & $\begin{array}{l}7.26(3.36) \\
6.97(0.53 \text { to } 14.99) \\
(6.97 \text { to } 7.55)\end{array}$ & & $\begin{array}{l}25.1(8.7) \\
22.1(15.0 \text { to } 78.2) \\
(24.6 \text { to } 25.6)\end{array}$ & $\begin{array}{l}28.2(9.7) \\
26.9(15.0 \text { to } 88.7) \\
(27.7 \text { to } 28.8)\end{array}$ & \\
\hline Gender & & & 1.00 & & & 1.00 \\
\hline Primary care physician & $1624(80.8 \%)$ & $1841(93.5 \%)$ & & $2593(79.8 \%)$ & $3004(93.5 \%)$ & \\
\hline Specialist (public care) & $316(15.7 \%)$ & $105(5.3 \%)$ & & $530(16.3 \%)$ & $178(5.5 \%)$ & \\
\hline Specialist (private care) & $71(3.5 \%)$ & $22(1.1 \%)$ & & $125(3.8 \%)$ & $32(1.0 \%)$ & \\
\hline $\begin{array}{l}\text { Number of medical care } \\
\text { visits } 2 \text { years prior to } \\
\text { surgery/no surgery }\end{array}$ & & & 1.00 & & & 1.00 \\
\hline 1 & $87(16.7 \%)$ & 87 (16.7\%) & & 330 (29.4\%) & $330(29.4 \%)$ & \\
\hline 2 & $100(19.2 \%)$ & $100(19.2 \%)$ & & $240(21.4 \%)$ & $240(21.4 \%)$ & \\
\hline 3 & 94 (18.0\%) & 94 (18.0\%) & & $216(19.3 \%)$ & $216(19.3 \%)$ & \\
\hline $\begin{array}{l}\text { Category (visits before } \\
\text { surgery/no surgery) }\end{array}$ & & & 1.00 & & & 1.00 \\
\hline A: $1-3$ visits & $281(53.8 \%)$ & $281(53.8 \%)$ & & $786(70.1 \%)$ & $786(70.1 \%)$ & \\
\hline B: $4-6$ visits & $162(31.0 \%)$ & $162(31.0 \%)$ & & 291 (25.9\%) & 291 (25.9\%) & \\
\hline C: $7+$ visits & 79 (15.1\%) & 79 (15.1\%) & & $45(4.0 \%)$ & $45(4.0 \%)$ & \\
\hline \multicolumn{7}{|l|}{ Follow-up } \\
\hline 1-year follow-up & 522 & 522 & 1.00 & 1122 & 1122 & 1.00 \\
\hline 2-year follow-up & 419 (80.3\%) & 437 (83.7\%) & 0.17 & 892 (79.5\%) & $922(82.2 \%)$ & 0.12 \\
\hline 3-year follow-up & 304 (58.2\%) & 357 (68.4\%) & 0.0008 & 659 (58.7\%) & 697 (62.1\%) & 0.11 \\
\hline
\end{tabular}

For categorical variables, $\mathrm{n}(\%)$ is presented. For continuous variables, mean (SD)/median (min; max)/(95\% Cl for mean) is presented.

\section{RESULTS}

\section{Study population}

Of a total of 255312 patients in the initial dataset retrieved from the VEGA register, 1644 tonsillectomy patients (522 children and 1122 adults) met the inclusion and exclusion criteria for the intervention group. An identical number of patients were selected for the control group with caliper matching, resulting in the inclusion of 522 children and 1122 adults in the intervention and control groups, respectively. The general characteristics of the study population are presented in table 1 . The gender distribution was almost even in children ( $51 \%$ female), in contrast to a 2/3 female majority in adults. Most children included were $\geq 5$ years, and almost all adults were younger than 40 years. Of the children, $64.2 \%$ underwent tonsillectomy and $35.8 \%$ underwent adenotonsillectomy. The mean number of registered visits for pharyngitis or tonsillitis prior to surgery in children was 3.85 (3.63 to 4.07 ) in the intervention group, 3.77 (3.57 to 3.97) in the control group and 2.89 (2.78 to 3.01) versus 2.86 (2.76 


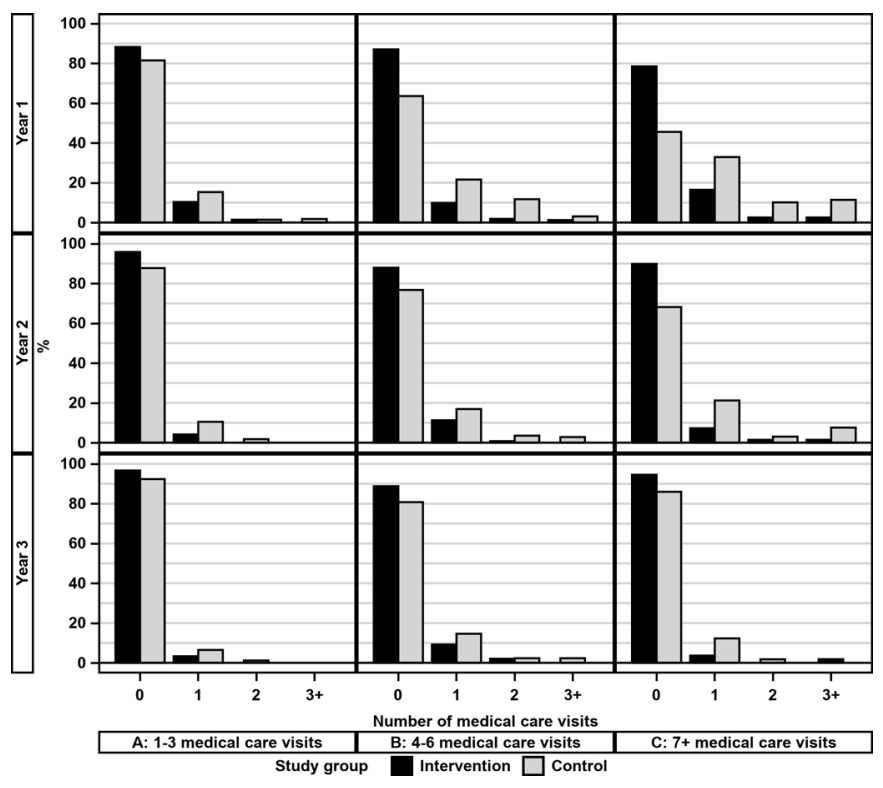

Figure 2 The histograms illustrate the number of medical care visits for pharyngitis and tonsillitis after surgery/fictive surgery for children. Categories A-C represent the number of medical care visits in the 2-year period before surgery/fictive surgery, category A (1-3 visits), category B (4-6 visits) and category $(7+$ visits). Most patients in both the intervention and control groups had none or a single medical care visit during the follow-up period. The same pattern was seen for adults (not shown in the figure).

to 2.97) in adults. Among the children and adults, $53.8 \%$ and $70.1 \%$, respectively, had 1-3 medical care visits in the 2-year period before surgery, while $15.1 \%$ of the children and $4.0 \%$ of the adults had $\geq 7$ visits before surgery. All patients had a minimum of 1 year of follow-up, and $80 \%$ of the patients were followed for 2 years, while $58 \%-68 \%$ of the patients were followed for 3 years, with no significant difference in follow-up time between the intervention and control groups except for the third year in children. The mean follow-up time was 2.39 versus 2.52 years for the intervention versus control group in children, and 2.38 versus 2.44 years in adults.

\section{Main results}

Most of the children and adults in both the intervention and control groups had none or a single medical care visit during the follow-up period (figure 2).

The effect of tonsillectomy/adenotonsillectomy in childrenchanges in medical care visit rates

In children who underwent tonsillectomy/adenotonsillectomy, there was a significant decrease in yearly medical care visit rates from 1.93 (1.82 to 2.04) before surgery to 0.129 (0.099 to 0.165$)$ after surgery, with a mean change of -1.80 ( -1.90 to -1.69$), \mathrm{p}<0.0001$. When comparing the children who underwent surgery with the control group, a significantly greater decrease in yearly mean medical care visit rates was observed in the surgical group, -1.80 $(-1.90$ to -1.69$)$ versus -1.51 ( -1.61 to -1.41$)$, with a mean difference of $-0.283(-0.436$ to -0.135$), p=0.0002$ (table 2).

The effect of tonsillectomy in adults—changes in medical care visit rates

A less pronounced but still significant decrease in yearly mean visit rates was observed in adults. The mean change in visit rates for the surgical group was $-1.30(-1.36$ to $-1.24), \mathrm{p}<0.0001$, a decrease from 1.45 (1.39 to 1.51) before surgery to 0.152 (0.132 to 0.173$)$ after surgery. As observed in children, the decrease in visit rates was greater in the surgical group with a change of $-1.30(-1.36$ to $-1.24)$ compared with the control group at $-1.18(-1.24$ to -1.13$)$. The mean difference of $-0.111(-0.195$ to $-0.028)$ between the groups was statistically significant ( $\mathrm{p}=0.0097$; table 2).

\section{Pattern of diagnostic codes}

Most of the visits before surgery/fictitious surgery were coded as tonsillitis (J03X), and after surgery, medical care visits were more frequently coded as tonsillitis instead of pharyngitis in the control group (figure 3). The largest difference between the intervention and control groups was the more frequent use of the code for chronic tonsillitis (J350) in the intervention group before surgery.

\section{Subgroup analysis}

The incidence rates per 100 person years, rate ratio, RRR and NNT for the different subgroups are presented in figure 4 .

Outcome depending on the number of medical care visits before surgery/no surgery (categories $\mathrm{A}-\mathrm{C}$ )

The forest plot demonstrates the effect of surgery in children and adults for all categories, separate and combined; however, the differences between the intervention and control groups were not statistically significant for all categories. In both children and adults, higher incidence rates of medical care visits after surgery/fictitious surgery were observed in patients with a higher number of visits before surgery/no surgery, and generally higher visit rates were seen in the intervention group compared with the control group. No systematic differences were observed in RRRs across the categories regardless of age. Lower NNTs were found in children who underwent surgery with $7+$ preoperative visits compared with children with a lower number of preoperative visits, with an NNT of 2 (2-5) the first year of follow-up and $3(2-8)$ the second year of follow-up. For adults, the same pattern was observed, with an NNT of 2 (1-3) the first year of follow-up for patients with $7+$ visits before surgery. For patients with 4-6 visits before surgery/fictitious surgery (category B), the NNT was $3(2-4)$ in children and 5 (3-11) in adults during the first year of follow-up and higher or not significant during the second and third years of follow-up. 
Table 2 Comparisons of yearly mean rate of medical care visits before and after surgery/fictive surgery and between intervention and control groups

\begin{tabular}{|c|c|c|c|}
\hline & Intervention (surgery) & Control (fictive surgery) & $\begin{array}{l}\text { Differences (between } \\
\text { groups) }\end{array}$ \\
\hline & $\begin{array}{l}\text { Mean } \\
\text { (95\% Cl for mean) median } \\
\text { (min; max) }\end{array}$ & $\begin{array}{l}\text { Mean } \\
\text { 95\% CI for mean } \\
\text { median (min; max) }\end{array}$ & $\begin{array}{l}\text { Mean } \\
95 \% \mathrm{Cl} \text { for mean }\end{array}$ \\
\hline \multicolumn{4}{|l|}{$\begin{array}{l}\text { Children ( }<15 \text { years }) \\
n=522\end{array}$} \\
\hline $\begin{array}{l}\text { Yearly rate of medical care visits before } \\
\text { (2 years) surgery/fictive surgery }\end{array}$ & $\begin{array}{l}1.93(1.82 \text { to } 2.04) \\
1.5(0.5 \text { to } 8.5)\end{array}$ & $\begin{array}{l}1.89(1.79 \text { to } 1.98) \\
1.5(0.5 \text { to } 7)\end{array}$ & $0.041(-0.107$ to 0.194$)$ \\
\hline $\begin{array}{l}\text { Yearly rate of medical care visits after } \\
\text { (up to } 3 \text { years) surgery/fictive surgery }\end{array}$ & $\begin{array}{l}0.129(0.099 \text { to } 0.165) \\
0(0 \text { to } 4.33)\end{array}$ & $\begin{array}{l}0.371(0.312 \text { to } 0.433) \\
0(0 \text { to } 7)\end{array}$ & $-0.241(-0.313$ to -0.174$)$ \\
\hline $\begin{array}{l}\text { Change in rate before and after } \\
\text { surgery/fictive surgery }\end{array}$ & $\begin{array}{l}-1.80(-1.90 \text { to }-1.69) \\
-1.5(-7 \text { to } 1)\end{array}$ & $\begin{array}{l}-1.51(-1.61 \text { to }-1.41) \\
-1.33(-7 \text { to } 4)\end{array}$ & $-0.283(-0.436$ to -0.135$)$ \\
\hline$P$ value & $<0.0001$ & $<0.0001$ & 0.0002 \\
\hline \multicolumn{4}{|l|}{$\begin{array}{l}\text { Adults }(\geq 15 \text { years) } \\
n=1122\end{array}$} \\
\hline $\begin{array}{l}\text { Yearly rate of medical care visits before } \\
\text { (2 years) surgery/fictive surgery }\end{array}$ & $\begin{array}{l}1.45(1.39 \text { to } 1.51) \\
1(0.5 \text { to } 10.5)\end{array}$ & $\begin{array}{l}1.43(1.38 \text { to } 1.49) \\
1(0.5 \text { to } 7.5)\end{array}$ & $0.015(-0.064$ to 0.094$)$ \\
\hline $\begin{array}{l}\text { Yearly rate of medical care visits after } \\
\text { (up to } 3 \text { years) surgery/fictive surgery }\end{array}$ & $\begin{array}{l}0.152(0.132 \text { to } 0.173) \\
0(0 \text { to } 3)\end{array}$ & $\begin{array}{l}0.248(0.213 \text { to } 0.288) \\
0(0 \text { to } 8)\end{array}$ & $-0.096(-0.141$ to -0.054$)$ \\
\hline $\begin{array}{l}\text { Change in rate before and after } \\
\text { surgery/fictive surgery }\end{array}$ & $\begin{array}{l}-1.30(-1.36 \text { to }-1.24) \\
-1(-10.5 \text { to } 1.5)\end{array}$ & $\begin{array}{l}-1.18(-1.24 \text { to }-1.13) \\
-1(-6.83 \text { to } 6)\end{array}$ & $-0.111(-0.195$ to -0.028$)$ \\
\hline$P$ value & $<0.0001$ & $<0.0001$ & 0.0097 \\
\hline
\end{tabular}

$P$ values for intervention and control groups are based on differences within groups as opposed to $p$ values for the differences which is calculated based on differences between the intervention and control groups. Patients have contributed with their maximum number of follow-up years in the calculation of means.

Outcome depending on the length of follow-up (first, second or third year after surgery/no surgery)

In both children and adults, higher incidence rates

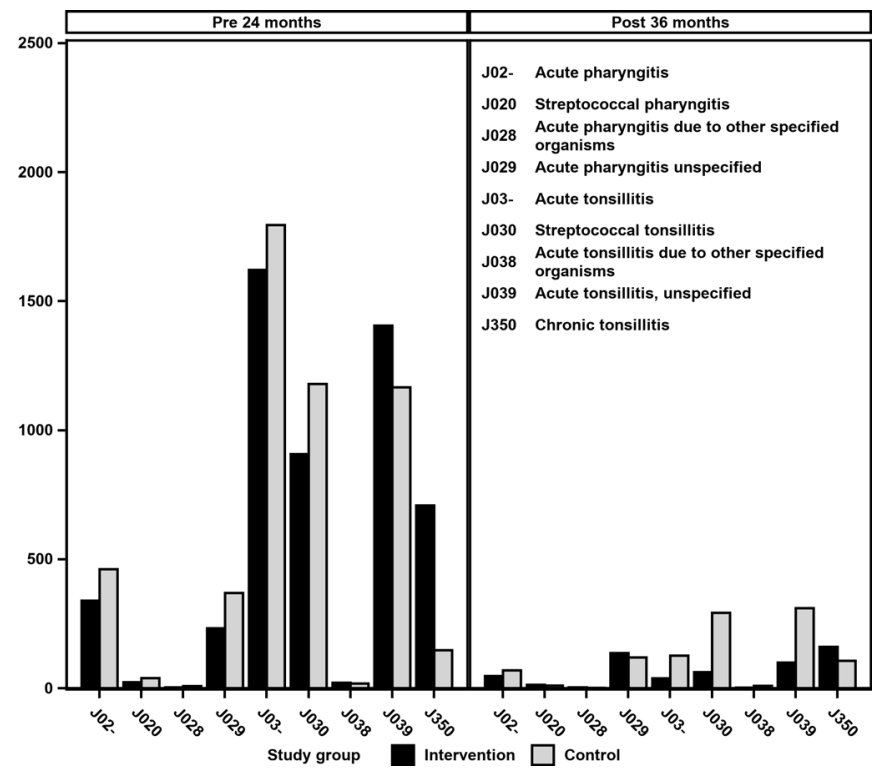

Figure 3 The distribution of medical care visits, based on ICD10 codes, before and after surgery/fictive surgery for the intervention and control groups. The y-axis shows the number of medical care visits. for medical care visits were observed the first year after surgery/fictitious surgery compared with the second and third years regardless of surgical intervention. For both surgical and non-surgical treated patients, the largest reductions in medical care visits happened within the first year of follow-up. As seen for the categories, no systematic pattern in RRRs related to the year of follow-up could be detected. The NNTs were lower in the first year of follow-up compared with the second and third years for most categories and did not reach statistical significance for the third year of follow-up for any category (A-C).

\section{DISCUSSION}

Both patients who underwent tonsillectomy and patients who did not had statistically fewer medical care visits after surgery/fictitious surgery. A significantly greater decrease in medical care visits was observed for patients who underwent surgery compared with patients who did not. The NNTs were unexpectedly high, indicating that tonsillectomy was not very effective in reducing medical care visits in children and adults with chronic/recurrent tonsillitis in our cohort. The improvement compared with no surgical treatment was small and of questionable clinical value considering the few medical care visits observed in the patients who did not undergo tonsillectomy. The 


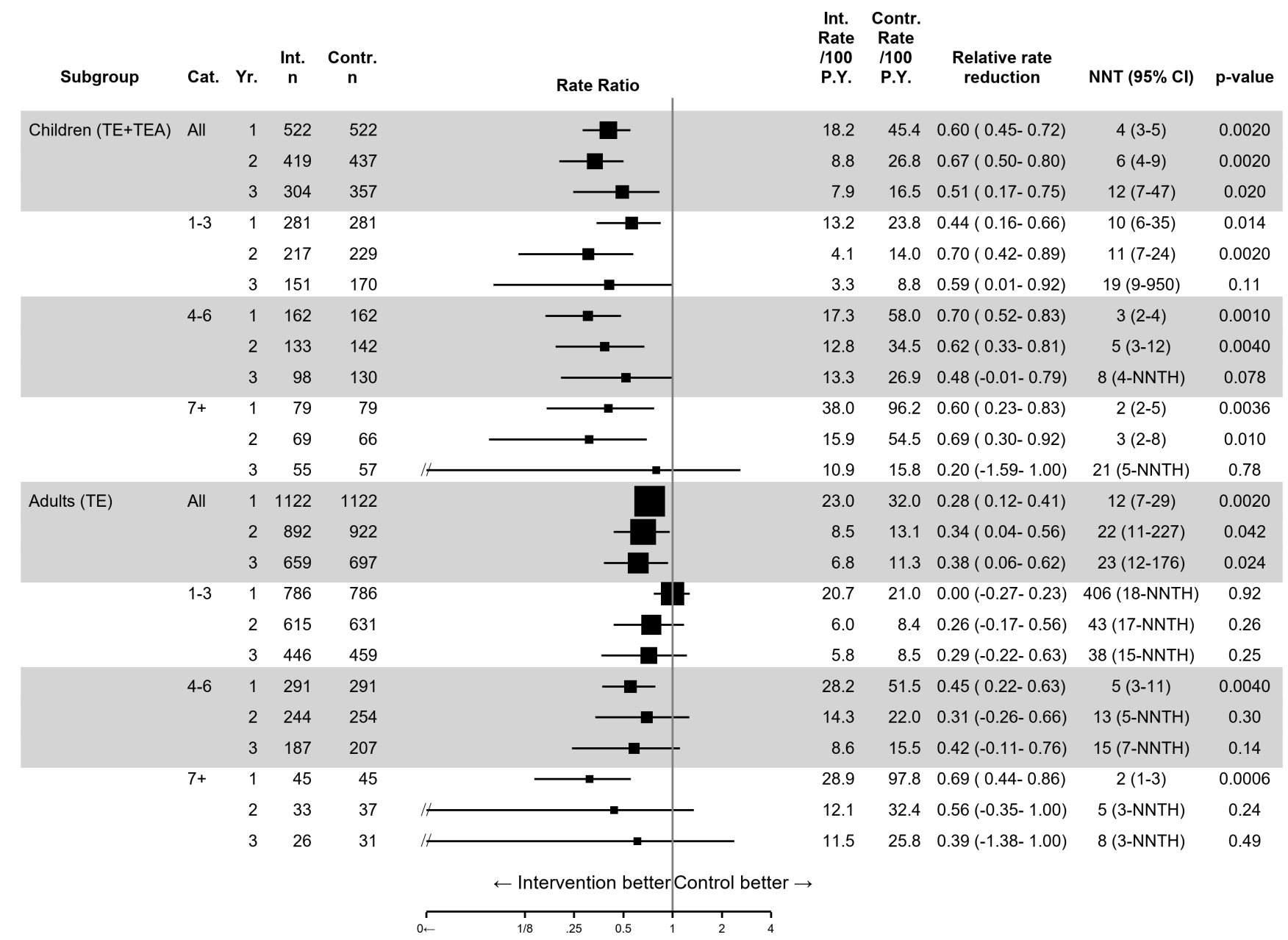

Figure 4 The forest plot demonstrates incidence rates per 100 person years (PYs), rate ratio, relative rate reductions, the numbers needed to treat (NNT) and $p$ values for calculation of rate ratios. Subgroup analyses are shown for children and adults, categories $\mathrm{A}-\mathrm{C}$ based on number of medical care visits before surgery/fictive surgery and follow-up years 1,2 or 3 . On the visual logarithmic scale for rate ratio, size of markings is proportional to size of $n$ in the relevant subgroup and $\mathrm{Cl}$ lines crossing the vertical line are not significant. Category A: 1-3 medical care visits before surgery/fictive surgery, category B: 4-6 medical care visits before surgery/fictive surgery and category C: 7+ medical care visits before surgery/fictive surgery. NNTH, number needed to harm; TE, tonsillectomy; TEA, adenotonsillectomy.

effect of surgery for most patients was greater in the first year of follow-up compared with the second and third years of follow-up. Children with a higher number of preoperative visits seemed to benefit more from the procedure, supported by lower NNTs. In adults, the effect of surgery was weaker compared with children, and only apparent the first year after surgery in adults with $\geq 4$ qualifying visits during the presurgery observation period.

This is the first retrospective cohort study of the effect of tonsillectomy on the number of postoperative medical care visits for throat infections in patients of all ages with chronic/recurrent tonsillitis. The sample size is large, and the outcome measure is objective with high validity given the coverage of the VEGA register. The strict matching criteria should minimise selection bias.

The study design did not allow control of the actual circumstances leading to a tonsillectomy decision in the operated group, and therefore all possible causal relationships between intervention and outcome should be interpreted with caution. It is possible that the group that underwent surgery comprised patients with more 'severe disease', exemplified by other measures of disease burden, such as a higher number of days with throat pain or more severe symptoms with each episode. Unfortunately, the VEGA register does not contain these variables. The 1:1 matching between intervention and control groups was only achieved for the first year of follow-up due to higher numbers of dropouts in the intervention groups, the category A patients (1-3 visits) and females, hence data for follow-up years 2 and 3 should be interpreted with more caution.

The Swedish guidelines for tonsillectomy on infectious indications do not differentiate between recurrent and chronic tonsillitis. ${ }^{16}$ The guidelines suggest that the following criteria should be met before tonsillectomy: throat pain due to tonsillitis with symptoms severe enough to affect daily activities and failure of conservative treatment with antibiotics. In regular cases, the patient should have had 3-4 episodes of tonsillitis during a 1-year to 2-year period. Because all tonsillectomies in 
this study were coded as J35.0 chronic tonsillitis at surgery (no specific code exists for recurrent tonsillitis in the ICD10 coding system), the distinction between surgery for chronic and recurrent tonsillitis was not possible. It is unclear whether chronic and recurrent tonsillitis comprise two different pathological entities, and the terms are inconsequently used in the literature. ${ }^{1}$ The excess of visits due to acute tonsillitis or acute pharyngitis prior to surgery in the intervention groups (figure 3) suggests that many of the patients in this study had recurrent infections. However, $16.7 \%$ of the children and $29.4 \%$ of the adults in our intervention group underwent surgery with only one qualifying medical care visit for pharyngitis or tonsillitis within the 24-month preceding surgery. Previous published data from the National Tonsil Surgery Register in Sweden showed that chronic tonsillitis was the main indication for surgery in $5.6 \%$ of tonsil operations in children and $28.8 \%$ in adults in Sweden (2013-2015). ${ }^{17}$ The population in our study is most likely a mix of patients with recurrent and chronic tonsillitis but it is possible that a larger share of the adults (compared with children) underwent surgery for chronic tonsillitis rather than recurrent infections and that this has influenced the observed effect of surgery in this group.

In this study, all throat infections were treated as one entity as the precision of coding in the VEGA register has not been validated. The results show that the precision could be improved, as patients without tonsils was diagnosed with tonsillitis in the follow-up period.

Regardless of the statistical distribution in our data, regression to the mean is likely part of the explanation for the low number of medical care visits observed in the follow-up period for both the intervention and control groups. The major reduction in medical care visits in the intervention and control groups apparent already the first year of follow-up supports this claim. However, given the strict matching, intergroup differences should have been unaffected by this phenomenon, and a relatively long observational period before (24 months) and after intervention/no intervention (12-36 months) should minimise this potential bias.

Paradise stated in his well-renowned studies that (adeno)tonsillectomy is indicated only in severely affected children with seven of more well-defined and documented throat infections in the preceding year, five or more in each of the last 2 years and three or more per year in the last 3 years. ${ }^{7}$ In his updated study in 2002 , the effect in children with moderate disease was studied (moderate was defined as three or more infections per year), and this showed a significantly lower infection rate in the surgical groups in each of the three follow-up years. In both the surgical and non-surgical groups, the rate of infections in the follow-up period was low, and the conclusion from this study was that the benefit of surgical intervention in moderately affected children did not justify the risks of surgery. ${ }^{8}$ Van Staaij et al made the same conclusion in a study of the effectiveness of adenotonsillectomy in children with mild symptoms of throat infections that surgery marginally reduced the number of throat infections, but the effect was small compared with watchful waiting. ${ }^{3}$ Alho et al reported less frequent episodes of sore throat after tonsillectomy in adults with three or more episodes of pharyngitis within 6 months or four within 12 months. ${ }^{9}$ Most of the patients in our study had six or fewer medical care visits for pharyngitis/tonsillitis in the 2 years preceding surgery, meaning that less than $15.1 \%$ of children and $4.0 \%$ of adults in our study had severe disease as defined by Paradise. Our findings of a reduction in medical care visits following tonsillectomy/adenotonsillectomy in children with $\geq 7$ medical care visits, but generally few medical care visits regardless of intervention, are consistent with the findings of Paradise and Van Staaiij. Counting the surgical event as one postoperative medical care visit in the intervention group year 1 of follow-up, as suggested by Burton et al, ${ }^{1}$ would have eliminated the differences between groups in the first year of follow-up, and favoured against surgery.

In the decision for tonsillectomy, the potential gain must be weighed against the risks of complications. The most significant complication of tonsil surgery is postoperative haemorrhage, which can result in urgent readmission to the hospital, return to the theatre and in rare instances, death. ${ }^{18-20}$ The procedure is also associated with several days of postoperative pain, and even with the standard use of postoperative analgesics, many patients report significant pain and discomfort. ${ }^{21}$ The small differences in mean visit rates between the patients who underwent surgery compared with those who did not, together with the low incidence rates of medical care visits in the patients who did not undergo surgery during the follow-up period, imply that the gain of tonsillectomy in the studied population may be questioned. Our results suggest that the threshold for surgical intervention in both children and adults moderately or less affected by chronic or recurrent throat infections needs to be further studied and discussed as most patients seem to improve spontaneously within a year without surgery. Another interpretation of this would be that the watchful waiting period before a final decision for surgery should last no longer than a year. From our study cohort, it is not possible to draw firm conclusions regarding the effect of tonsillectomy in severely affected patients, because few patients fulfilled the Paradise criteria for number of qualifying episodes of throat infections, and no information about the severity of the episodes was available in the VEGA register.

Acknowledgements The authors acknowledge statisticians Bengt Bengtsson and Nils-Gunnar Pehrsson at Statistiska Konsultgruppen for assistance with the statistical analyses.

Contributors All authors contributed to the study design, analysis and interpretation of data. The corresponding author (EO) drafted the manuscript, and both coauthors (OS and JS) critically reviewed the manuscript and provided important intellectual input. The corresponding author attests that all authors meet the required authorship criteria, and that no others meeting the criteria have been omitted. 
Funding This research was supported by a grant from the health care region Västra Götaland, and a personal research grant to the corresponding author from the Gothenburg Society of Medicine and Acta Oto-Laryngologica.

Disclaimer Dissemination of the results to patients or patient organizations is not possible/applicable.

Competing interests None declared.

Patient consent for publication Not required.

Ethics approval The study was approved by the regional ethical board in Gothenburg, Sweden (Dnr. 257-14).

Provenance and peer review Not commissioned; externally peer reviewed.

Data availability statement All data relevant to the study are included in the article. Additional data are available upon reasonable request (i.e detailed data from the sensitivity and drop-out analyses).

Open access This is an open access article distributed in accordance with the Creative Commons Attribution Non Commercial (CC BY-NC 4.0) license, which permits others to distribute, remix, adapt, build upon this work non-commercially, and license their derivative works on different terms, provided the original work is properly cited, appropriate credit is given, any changes made indicated, and the use is non-commercial. See: http://creativecommons.org/licenses/by-nc/4.0/.

ORCID iD

Eirik Østvoll http://orcid.org/0000-0003-4708-2309

\section{REFERENCES}

1 Burton MJ, Glasziou PP, Chong LY, et al. Tonsillectomy or adenotonsillectomy versus non-surgical treatment for chronic/ recurrent acute tonsillitis. Cochrane Database Syst Rev 2014:CD001802.

2 Windfuhr JP, Toepfner N, Steffen G, et al. Clinical practice guideline: tonsillitis II. surgical management. Eur Arch Otorhinolaryngol 2016;273:989-1009.

3 van Staaij BK, van den Akker EH, Rovers MM, et al. Effectiveness of adenotonsillectomy in children with mild symptoms of throat infections or adenotonsillar hypertrophy: open, randomised controlled trial. BMJ 2004;329:651-6.

4 Morad A, Sathe NA, Francis DO, et al. Tonsillectomy versus watchful waiting for recurrent throat infection: a systematic review. Pediatrics 2017; 139:e20163490.

5 Windfuhr JP. Indications for tonsillectomy stratified by the level of evidence. GMS Curr Top Otorhinolaryngol Head Neck Surg 2016;15:Doc09.
6 Mitchell RB, Archer SM, Ishman SL, et al. Clinical Practice Guideline: Tonsillectomy in Children (Update) - Executive Summary. Otolaryngol Head Neck Surg 2019;160:187-205.

7 Paradise JL, Bluestone CD, Bachman RZ, et al. Efficacy of tonsillectomy for recurrent throat infection in severely affected children. Results of parallel randomized and nonrandomized clinical trials. N Engl J Med 1984;310:674-83.

8 Paradise JL, Bluestone CD, Colborn DK, et al. Tonsillectomy and adenotonsillectomy for recurrent throat infection in moderately affected children. Pediatrics 2002;110:7-15

9 Alho O-P, Koivunen P, Penna T, et al. Tonsillectomy versus watchful waiting in recurrent streptococcal pharyngitis in adults: randomised controlled trial. BMJ 2007;334.

10 Koskenkorva T, Koivunen P, Koskela M, et al. Short-Term outcomes of tonsillectomy in adult patients with recurrent pharyngitis: a randomized controlled trial. Can Med Assoc J 2013;185:E331-6.

11 Van Den Akker EH, Hoes AW, Burton MJ, et al. Large international differences in (adeno)tonsillectomy rates. Clin Otolaryngol Allied Sci 2004;29:161-4

12 Windfuhr JP. Specified data for tonsil surgery in Germany. GMS Curr Top Otorhinolaryngol Head Neck Surg 2016;15:Doc08.

13 Powell J, O'Hara J, Carrie S, et al. Is tonsillectomy recommended in adults with recurrent tonsillitis? BMJ 2017;357:j1450.

14 The Nordic Medico-Statistical Committee, NOMESCO Classification of Surgical Procedures (NCSP). Yearly updates only in Norwegian available from the Norwegian Directorate for e-health, Copenhagen, 2010. Available: www.ehelse.no

15 Ludvigsson JF, Andersson E, Ekbom A, et al. External review and validation of the Swedish national inpatient register. BMC Public Health 2011;11:450.

16 The Swedish Association of Local Authorities and Regions. Report on national medical indications for tonsil surgery in Sweden. Stockholm, 2009. Available: www.tonsilloperation.se

17 Hallenstål N, Sunnergren O, Ericsson E, et al. Tonsil surgery in Sweden 2013-2015. indications, surgical methods and patientreported outcomes from the National tonsil surgery register. Acta Otolaryngol 2017;137:1096-103.

18 Østvoll E, Sunnergren O, Stalfors J. Increasing readmission rates for hemorrhage after tonsil surgery: a longitudinal (26 years) national study. Otolaryngol Head Neck Surg 2018;158:167-76.

19 Sarny S, Ossimitz G, Habermann W, et al. Hemorrhage following tonsil surgery: a multicenter prospective study. Laryngoscope 2011;121:2553-60.

20 Østvoll E, Sunnergren O, Ericsson E, et al. Mortality after tonsil surgery, a population study, covering eight years and 82,527 operations in Sweden. Eur Arch Otorhinolaryngol 2015;272:737-43.

21 Guntinas-Lichius O, Geißler K, Komann M, et al. InterHospital variability of postoperative pain after tonsillectomy: prospective registry-based multicentre cohort study. PLoS One 2016;11:e0154155. 